\title{
KEMAMPUAN MENYIMAK ANAK USIA 3-4 TAHUN DALAM KEGIATAN BERCERITA DI PPT TANJUNG IX KENJERAN SURABAYA
}

\author{
Andini Hardiningrum, S.Pd.,M.Pd \\ (Universitas Nahdlatul Ulama Surabaya, andinihardiningrum@unusa.ac.id) \\ Jauharotur Rihlah., S.Pd.,M.Pd \\ (Universitas Nahdlatul Ulama Surabaya, rihlahjauhara@unusa.ac.id)
}

\begin{abstract}
Abstrak : Kemampuan berbahasa saling mempengaruhi satu sama lain. Sebelum anak mampu berbicara, membaca, dan menulis anak terlebih dahulu menyimak. Menyimak merupakan kemampuan yang paling awal dipelajari oleh anak diantara tiga kemampuan lainnya. Hal ini dijelaskan juga oleh Tarigan (2008:2) "pada masa kecil kita belajar menyimak bahasa kemudian berbicara, sesudah itu kita membaca dan menulis". Kegiatan di PPT yang mampu mengembangkan kemampuan menyimak anak diantaranya melalui kegiatan bercerita. Dengan bercerita pendengaran anak dapat difungsikan dengan baik untuk membantu kemampuan berbicara, dengan menambah perbendaharaan kosa kata, kemampuan mengucap kata-kata, melatih merangkai kalimat sesuai dengan tahap perkembangannya. Desain Penelitian yang digunakan adalah Penelitian Deskriptif kualitatif. Subjek penelitian ini yaitu anak usia 3-4 tahun di PPT Tanjung IX Kenjeran Surabaya. Dari hasil penelitian Kemampuan menyimak adalah kemampuan yang dapat dimiliki oleh anak melalui bimbingan, pada anak kelompok A PPT Tanjung IX Kenjeran Surabaya kemampuan menyimak anak berdasarkan hasil penelitian masih dalam tahap mulai berkembang. Untuk mencapai tahap sudah berkembang dan berkembang sangat baik guru harus membimbing dan melatih anak. Teknik analisis data model Miles dan Huberman ada 3 langkah yaitu, data reduction (reduksi data), data display (penyajian data), dan conclusion drawing/verification.. Simpulan dari penelitian ini adalah Anak sudah dalam tahap mulai berkembang sesuai dengan indikator yang diharapkan. Faktor situasi adalah faktor yang paling banyak mempengaruhi kemampuan menyimak anak dalam kegitan bercerita. Metode yang digunakan oleh guru di PPT Tanjung IX Kenjeran Surabaya adalah metode simak ulang ucap, simak kerjakan, menjawab pertanyaan dan paraphrase.
\end{abstract}

\section{Kata Kunci; Kemampuan Menyimak, Kegiatan Bercerita.}

Abstract: Language skills affect each other. Before the child is able to speak, read, and write the child first listens. Listening is the earliest ability a child learns among the three other abilities. This is explained also by Tarigan (2008: 2) "in childhood we learn to listen to language then speak, after that we read and write". PPT activities that are able to develop the ability to listen to children through storytelling activities. By telling a child's hearing can be functioned well to help the ability to speak, by increasing vocabulary vocabulary, the ability to say words, train stringing sentences in accordance with the stage of development. The research design used is qualitative descriptive research. The subjects of this study were children aged 3-4 years in PPT Tanjung IX Kenjeran Surabaya. From the results of research the ability to listen is the ability that can be possessed by children through guidance, in group A PPT Tanjung IX Kenjeran Surabaya children the ability to listen to children based on research results is still in the developing stages. To reach the stage it has developed and is developing very well the teacher must guide and train the child. The data analysis technique of the Miles and Huberman model consists of 3 steps namely, data reduction, data display, and conclusion drawing / verification. The conclusion of this study is that the child is in the stage of developing according to the expected indicators. Situation factors are the factors that most influence the ability to listen to children in storytelling activities. The method used by teachers in PPT Tanjung IX Kenjeran Surabaya is the method of recounting, working on it, answering questions and paraphrase.

Keywords; Ability to Listen, Storytelling Activities 


\section{PENDAHULUAN}

Masa usia dini merupakan masa tumbuh dan berkembangnya seorang anak. Segala aspek yang ada pada diri anak berkembang sangat pesat. Baik dari segi fisik maupun psikologi dan intelegensinya. Seperti yang dikatakan Susanto (2011:5) "anak berkembang sangat pesat dalam berbagai aspeknya, tidak hanya dari segi fisik semata melainkan juga dari segi psikologi hingga intelegensinya".

Perkembangan bahasa pada masa anak-anak sangat berpengaruh terhadap kehidupannya di masa mendatang, sebab akan lebih susah mengajarkan bahasa kepada anak yang sudah berada pada usia Sekolah Dasar (SD) keatas. Hal ini dijelaskan oleh Pieget (dalam Seefeldt \& Wasik, 2008:19) "semakin belia anak, semakin sulit mengajarnya, dan semakin penulah pengajaran itu dengan akibat di kemudian hari”. Untuk itu kemampuan berbahasa harus sedini mungkin dikembangkan.

Kemampuan berbahasa ada 4 macamnya, seperti yang dikatakan Broomley (dalam Dhieni, 2008:1.19) "empat macam bentuk bahasa yaitu menyimak, berbicara, membaca dan menulis". Keempat macam kemampuan berbahasa tersebut saling mempengaruhi satu sama lain. Sebelum anak mampu berbicara, membaca, dan menulis anak terlebih dahulu menyimak. Menyimak merupakan kemampuan yang paling awal dipelajari oleh anak diantara tiga kemampuan lainnya. Hal ini dijelaskan juga oleh Tarigan (2008:2) "pada masa kecil kita belajar menyimak bahasa kemudian berbicara, sesudah itu kita membaca dan menulis".

Menyimak memiliki beberapa tahapan, yaitu meliputi menyimak berkala, menyimak dengan perhatian dangkal, setengah menyimak, menyimak serapan, menyimak sekali-sekali, menyimak asosiatif, menyimak dengan reaksi berkala, menyimak secara seksama, dan menyimak secara aktif. Untuk bisa menguasai kemampuan menyimak secara aktif anak memerlukan bimbingan dan pengajaran orang dewasa. Kemampuan menyimak itu tidak serta merta dikuasai anak, kemampuan menyimak perlu dikembangakan dan dipelajari anak melalui bimbingan. Oleh sebab itu kemampuan menyimak dimasukkan ke dalam kurikulum TK, agar anak dapat memperoleh pengalaman dan bimbingan sesuai usia dan kebuthan anak. seperti yang dikatakan oleh Kupetz \& Twiest (dalam Seefeldt \& Wasik, 2008:353) "menyimak itu bukan kemampuan alami sejak lahir, kemampuan ini perlu dipelajari lewat bimbingan dan pengajaran orang tua, para guru, dan orang lain di lingkungan anak-anak usia 3-5 tahun”.

\section{METODE PENELITIAN}

Penelitian ini menggunakan pendekatan penelitian deskriptif kualitatif. Menurut Hutomo (dalam Bungin, 2011:93) "penelitian kualitatif deskriptif artinya mencatat secara 
teliti segala gejala (fenomena) yang dilihat dan didengar serta dibacanya (melalui wawancara atau bukan, catatan lapangan, foto, video, tape, dokumen pribadi, catatan atau memo, dokumen resmi atau bukan, dan lain-lain) dan peneliti harus membanding- bandingkan, mengombinasikan, mengabstraksikan, dan menarik kesimpulan”.

Teknik pengumpulan data menggunakan observasi, wawancara dan dokumentasi. Teknik analisi data menggunakan model Miles dan Huberman ada 3 langkah yaitu, data reduction (reduksi data), data display (penyajian data), dan conclusion drawing/verification (Sugiyono, 2011:247-253). Bila peneliti melakukan pengumpulan data dengan trianggulasi, maka sebenarnya peneliti mengumpulkan data yang sekaligus menguji kreadibilitas data, yaitu mengecek kreadibilitas data dengan teknik pengumpulan data dan berbagai sumber data.

\section{HASIL DAN DISKUSI}

1. Kemampuan menyimak anak kelompok A dalam kegiatan bercerita di PPT Tanjung IX Kenjeran Surabaya

Berdasarkan hasil penelitian tentang kemampuan menyimak anak kelompok A dalam kegiatan bercerita di PPT Tanjung IX Kenjeran Surabaya dengan subyek penelitian 5 anak dan dengan 4 indikator. Dimana di setiap indikator ada 4 kriteria penilaian yang disesuaikan dengan tiap-tiap indikator. Penilaian berupa bintang yaitu bintang 1, bintang 2, bintang 3, dan bintang 4 . Berikut penjelasan rinci tiap-tiap indicator.

Jadi pada kemampuan menyimak anak kelompok A di PPT Tanjung IX Kenjeran Surabaya anak masih dalam tahap mulai berkembang, masih belum pada tahap sudah berkembang dengan baik (bintang 3) dan anak yang berkembang sangat baik (bintang 4).

Kemampuan menyimak adalah kemampuan yang dapat dimiliki oleh anak melalui bimbingan, pada anak kelompok A PPT Tanjung IX Kenjeran Surabaya kemampuan menyimak anak berdasarkan hasil penelitian masih dalam tahap mulai berkembang. Untuk mencapai tahap sudah berkembang dan berkembang sangat baik (Kemendiknas, $\left.2010^{\mathrm{b}}: 11\right)$ guru harus membimbing dan melatih anak. Seperti yang dikatakan oleh Kupetz \& Twiest (dalam Seefeldt \& Wasik, 2008:353) "menyimak itu bukan kemampuan alami sejak lahir, kemampuan ini perlu dipelajari lewat bimbingan dan pengajaran orang tua, para guru, dan orang lain di lingkungan anak-anak usia 3-5 tahun".

2. Faktor-faktor yang mempengaruhi kemampuan menyimak anak kelompok A dalam kegiatan bercerita di PPT Tanjung IX Kenjeran Surabaya Faktor-faktor yang mempengaruhi kemampuan menyimak anak kelompok A dalam kegiatan bercerita di 
PPT Tanjung IX Kenjeran Surabaya ada 3, yaitu faktor penyimak, faktor situasi, dan faktor pembicara. Dari kesepuluh anak yang diteliti ada 5 anak yang kemampuan menyimaknya dipengaruhi oleh faktor penyimak sendiri. Pada faktor situasi ada 6 anak yang dipengaruhi oleh faktor tersebut. Dan ada 2 anak yang dipengaruhi oleh faktor pembicara. Ada beberapa anak yang kemampuan menyimaknya dalam kegiatan bercerita dipengaruhi oleh 2 faktor, ada 4 anak yang dipengaruhi oleh faktor penyimak dan faktor situasi. Ada satu anak yang dipengaruhi oleh faktor situasi dan faktor pembicara. Dan ada satu anak yang dipengaruhi oleh faktor penyimak dan faktor pembicara.

Dari hasil penelitian tersebut faktor yang paling banyak mempengaruhi kemampuan menyimak anak kelompok A dalam kegiatan bercerita di PPT Tanjung IX Kenjeran Surabaya adalah faktor situasi. Dimana situasi yang meliputi stimulasi visual dan lingkungan kurang mendukung anak untuk dapat menyimak dengan baik. Stimulasi visual seperti papan tulis, gambar, maupun diagram dapat digunakan guru untuk membantu anak memahami materi yang diberikan. Guru sudah menyediakan gambar yang dapat menunjang atau membantu anak dalam memahami materi atau cerita. Namun karena kondisi lingkungan yang kurang kondusif dan tenang membuat anak terganggu dalam menyimak. Terdengar suara atau bunyi dari kelas sebelah yang gaduh, ruangan yang kurang sejuk karena kipas angin yang digunakan tidak berfungsi dengan baik.

3. Metode pengembangan kemampuan menyimak apa yang digunakan guru untuk mengembangkan kemampuan menyimak anak kelompok A dalam kegiatan bercerita di PPT Tanjung IX Kenjeran Surabaya.

Metode yang digunakan oleh guru dalam mengembangkan kemampuan menyimak anak kelompok A dalam kegiatan bercerita di PPT Tanjung IX Kenjeran Surabaya adalah metode simak- ulang-ucap, simak kerjakan, menjawab pertanyaan dan paraphrase. Dari hasil penelitian pada metode simak ulang ucap dan metode simak kerjakan kesepuluh anak mampu melakukan sesuai dengan apa yang diharapkan dari metode tersebut. Untuk metode menjawab pertanyaan ada 3 anak yang mampu menjawab pertanyan yang diajukan oleh guru. Dan untuk metode paraphrase ada 2 anak yang sesuai dengan harapan yang diingkan dari metode paraphrase tersebut.

\section{KESIMPULAN}

Simpulan dari penelitian ini adalah Anak sudah dalam tahap mulai berkembang sesuai dengan indikator yang diharapkan. Faktor situasi adalah faktor yang paling banyak mempengaruhi 
kemampuan menyimak anak dalam kegitan bercerita. Metode yang digunakan oleh guru di PPT Tanjung IX Kenjeran Surabaya adalah metode simak - ulang ucap, simak kerjakan, menjawab pertanyaan dan paraphrase. Sarannya Dalam meningkatkan kemampuan menyimak anak dalam kegiatan bercerita guru harus lebih berperan aktif dan memberi motivasi serta membimbing anak. Agar anak lebih tertarik dalam mendengarkan cerita yang dibawakan, guru harus lebih banyak menyediakan cerita- cerita sederhana dan menarik untuk disimak anak. Agar kemampuan anak dapat terlatih dan berkembang

\section{DAFTAR PUSTAKA}

Dhieni, Nurbiani. 2008. Metode Pengembangan Bahasa. Jakarta: Universitas Terbuka.

Nuraini, Isti. 2012. Meningkatkan Kemampuan Berbahasa Melalui Metode Bercerita Menggunakan Boneka Tangan Pada Anak Kelompok A TK Subulussalam Blawe Kabupaten Kediri. Skripsi tidak diterbitkan. Surabaya: PG.PAUD FIP UNESA.

Seefeldt, Caroldan Barbara A. Wasik. 2008. Pendidikan Anak Usia Dini Menyiapkan Anak Usia Tiga Empat Dan Lima Tahun Masuk Sekolah. Jakarta : Indeks.

Sugiyono. 2011. Metode Penelitian Kuantitatif, Kualitatif Dan R\&D. Bandung: Alfabeta.

Sujiono, Yuliani Nurani 2009. Konsep Dasar Pendidikan Anak Usia Dini. Jakarta: PT Indeks

Susanto, Ahmad. 2011. Perkembangan Anak Usia Dini Pengantar Dalam Berbagai Aspeknya. Ciputat: Prenada Media Group

Tarigan, Henry Guntur. 2008. Menyimak Sebagai Suatu Keterampilan Berbahasa. Bandung: Angkasa Bandung

Wahyuni, Sri. 2012. Peningkatan Kemampuan Menyimak Melalui Penerapan Metode Bercerita Pada Anak Kelompok A Di TK Al-Amin Rungkut Surabaya. Skripsi tidak diterbitkan. Surabaya: PG.PAUD FIP UNESA. 